\title{
BMJ Open Economic burden of multidrug-resistant bacteria in nursing homes in Germany: a cost analysis based on empirical data
}

\author{
Claudia Huebner, Marcus Roggelin, Steffen Flessa
}

To cite: Huebner C, Roggelin M, Flessa S. Economic burden of multidrug-resistant bacteria in nursing homes in Germany: a cost analysis based on empirical data. BMJ Open 2016;6:e008458.

doi:10.1136/bmjopen-2015008458

- Prepublication history for this paper is available online. To view these files please visit the journal online (http://dx.doi.org/10.1136/ bmjopen-2015-008458).

Received 10 April 2015 Revised 15 October 2015 Accepted 16 October 2015

\section{ABSTRACT \\ Objectives: Infections and colonisations with} multidrug-resistant organisms (MDROs) increasingly affect different types of healthcare facilities worldwide. So far, little is known about additional costs attributable to MDROs outside hospitals. The aim of this study was to analysis the economic burden of multidrug-resistant bacteria in nursing homes in Germany.

Setting: The cost analysis is performed from a microeconomic perspective of the healthcare facilities. Study took place in six long-term care facilities in north-eastern Germany.

Participants: Data of 71 residents with a positive MDRO status were included.

Primary and secondary outcome measures: The study analysed MDRO surveillance data from 2011 to 2013. It was supplemented by an empirical analysis to determine the burden on staff capacity and materials consumption.

Results: 11793 days with a positive multidrugresistant pathogen diagnosis could be included in the analysis. On average, $11.8(\mathrm{SD} \pm 6.3) \mathrm{MDRO}$ cases occurred per nursing home. Mean duration per case was 163.3 days $\left(\mathrm{SD}_{ \pm} 97.1\right)$. The annual MDR0-related costs varied in nursing homes between $€ 2449.72$ and $€ 153263.74$ on an average $€ 12682.23$ per case. Main cost drivers were staff capacity (€43.95 per day and $€ 7177.04$ per case) and isolation materials ( $€ 24.70$ per day and $€ 4033.51$ per case).

Conclusions: The importance of MDROs in nursing homes could be confirmed. MDR0-related cost data in this specific healthcare sector were collected for the first time. Knowledge about the burden of MDROs will enable to assess the efficiency of hygiene intervention measures in nursing homes in the future.

\section{INTRODUCTION}

Infections and colonisations with multidrug-resistant organisms (MDROs) are a worldwide known problem with steadily increasing importance that is no longer limited to hospitals and also concerns more and more other healthcare facilities such as nursing homes. ${ }^{1-6}$
Strengths and limitations of this study

- Cost data relating to multidrug resistance in long-term care facilities in combination with infection surveillance data have been collected for the first time.

- A time horizon of 3 years (2011-2013) was considered and evaluated.

- The analysis based on real cost data, which have been divided into eight cost categories.

- Study results are basis for assessment of efficiency of specific hygiene intervention measures in nursing homes.

- There are a small number of participating nursing homes and a strong regional constriction. An expansion of the study population, especially to other regions/countries, would weaken the meaningfulness of study results.

Elderly nursing home residents have several risk factors for colonisation or infection with MDROs, as defined by the German Commission for Hospital Hygiene and Infection Prevention (KRINKO). ${ }^{7}$ In particular, chronic diseases, multimorbidity, immune deficiencies, limited mobility and frequent transfers between hospital and nursing home lead to an increased risk of healthcare-associated infections ${ }^{8}$ and, consequently, the carriage of nosocomial multidrug-resistant pathogens. ${ }^{9}{ }^{10}$ In contrast to domestic and outpatient care, for inpatient care, a high proportion of intensely nursing-dependent persons (category III) can be recognised. ${ }^{11}$ It involves an additional risk for MDROs.

To counteract the spread and transmission of multidrug-resistant pathogens, protective hygienic measures must be introduced. In 2005, KRINKO published recommendations on infection prevention for nursing homes. ${ }^{12}$ In another recommendation, KRINKO addressed specifically the management of multidrug-resistant pathogens in healthcare facilities. These recommended procedures of infection control are associated with 
additional costs for the facilities. While there already exist several microcosting analyses regarding multidrug-resistant pathogens in hospitals, ${ }^{13-16}$ studies of additional costs attributable to MDROs in long-term facilities are rare $^{17}$ and not available for Germany. However, the knowledge of these data is needful to estimate the costs of different preventive measures, to provide adequate financial compensation of additional expenditures and, consequently, to determine the most cost-effective intervention.

The aim of this paper is an empirical analysis of the economic burden of multidrug-resistant bacteria in nursing homes. For this purpose, relevant hygiene processes and main cost drivers will be identified and assessed. The cost analysis is performed from the microeconomic perspective of the facilities. ${ }^{18}$

\section{METHODS}

Study design

The study is based on data of documented cases with MDROs (methicillin-resistant Staphylococcus aureus (MRSA), multidrug-resistant Gram-negative bacteria being resistant to three of the four classes of antibiotics (3-MRGN) and multidrug-resistant Gram-negative bacteria being resistant to four of the four classes of antibiotics (4-MRGN)). Vancomycin-resistant enterococci (VRE) have not been included in the analysis. Data recorded MDRO cases over a 3-year period from 2011 to 2013 in six nursing homes in Mecklenburg-Western Pomerania (northeast Germany, county Western Pomerania-Ruegen).

\section{MDRO cases}

MDRO infections and colonisations were grouped together to the term MDRO case. This was justified by the fact that the hygiene measures for all MDRO-positive residents have to be undertaken independently of an infection or colonisation; therefore, the calculable costs are comparatively high. There was no separate screening of multidrug-resistant pathogens carried out in the study. Therefore, all positive MDRO diagnoses were detected during a previous hospitalisation and patients were (re)admitted with this status to the nursing homes. If possible, decolonisation measures have been conducted based on the KRINKO recommendations from 1999. ${ }^{7}$ This includes treatment with mupirocin nasal ointment, washing of skin and hair with antiseptic products, application of antiseptic mouthwash and surface disinfection for at least 3 days. The 'average duration of an MDRO case' is defined as the mean number of days with positive MDRO diagnose. Normally, the status is terminated by negative control swab or death/transfer of residents. According to the KRINKO recommendations, negative controls include three negative swabs from 3 consecutive days after decolonisation. Decolonisation cycles have to be repeated ones or several times in case of eradication failure.
Personal resident data (age, sex, MDRO carrier status and length of MDRO case) were taken retrospectively from in-house patients records. These data were supplemented with information on infrastructure of the participating facilities.

Following recommendation of the German Hospital Information Surveillance System of MRSA (MRSAKISS) ${ }^{19}$ specific ratios were calculated:

$$
\begin{aligned}
& \text { MRSA_incidence density }=\frac{\text { number of MRSA cases }}{1000 \text { resident days }} \\
& \text { MRSA_burden }=\frac{\text { number of MRSA cases }}{100 \text { resident days }}
\end{aligned}
$$

\section{Process analysis and cost calculation}

In a first step, a process analysis was performed by internships in the nursing homes and studying of in-house standard operating procedures. Here, all relevant processes regarding the hygiene management of MDRO in the facilities were identified. Afterwards, these processes were assessed by time measurements and the documentation of consumed materials. In support of the empirical analysis, a separate survey form was developed. Staff working time incurred for specific activities in the MDRO hygiene management was measured in minutes by stopwatch and rated with the wage rate per minute (determined from the average monthly gross salary for nurses). Material uses were monitored and assessed with the respective purchase prices of the nursing homes.

The considered cost categories which referred to the different infection control precautions identified in the process analysis were: isolation (blocked beds in shared rooms), isolation materials, staff capacity (donning and doffing of personal protective equipment), information dissemination, cleaning and disinfection costs, laundry preparation, cost for patient-related use of medical equipment (sphygmomanometer with stethoscope, heart rate monitor, blood glucose meter, thermometer) and special preparation of diet. A distinction was made whether the costs incurred only once per case (fall fix costs) or regular in the context of hygiene measures (daily costs).

\section{Revenue analysis}

The calculated costs were compared with the revenues. For this purpose, an average revenue per year and nursing home was calculated, which is composed of the payments of the long-term care insurance and the payments of the residents. The payment amounts are dependent on the level of care (I-III) of the residents. ${ }^{20}$

\section{RESULTS}

\section{Data of residents}

Six nursing homes participated in the study. The average number of beds was $95.2(\mathrm{SD} \pm 14.6)$. 
Overall, 71 records of nursing home residents (52 females, 19 males, average age 80.3 years, $\mathrm{SD} \pm 4.7$ years) with a known positive MDRO carrier status (60 MRSA, 10 3-MRGN, 1 4-MRGN) could be evaluated. This corresponds to an average of $11.8(\mathrm{SD} \pm 6.3)$ cases per nursing home, respectively, on average 3.9 new cases per nursing home and year. Together, 11793 days with a multidrug-resistant pathogen carrier ship could be included in the analysis. The average duration per case was 163.3 days $(\mathrm{SD} \pm 97.1)$. Table 1 gives a detailed overview.

Most MDRO carriages were caused by MRSA (84.5\%). On average, during the 3-year study period, 10.0 (SD $\pm 5.5)$ MRSA cases occurred per nursing home, in comparison to $2.2(\mathrm{SD} \pm 2.0)$ MRGN cases per nursing home. However, the ratio varied widely among facilities. The mean MRSA incidence density was 0.094 ( $\mathrm{SD} \pm 0.047$ ), the mean MRSA burden was calculated with 1.60 (SD \pm 0.92 ). Table 2 shows a comparison of the results with MRSA-KISS data of the German National Reference Centre for hospitals and rehabilitation facilities.

The analysed time series showed that the number of days with a positive MDRO status had increased in the 3 years. Compared to 2011, in 2013, the number was higher by the factor 2.33 (average MDRO days per nursing home: 381.4 in 2011, 886.5 in 2013).

\section{Cost data}

Fall fix costs were calculated as $€ 233.87$ per case. In addition, daily costs due to hygiene measures incurred in the amount of $€ 76.23$. This totals in $€ 12682.23$ per case. The largest share belonged to cost of staff capacity ( $€ 43.95$ per day and $€ 7177.04$ per case) and the cost of isolation materials ( $€ 24.70$ per day and $€ 4033.51$ per case). Opportunity costs due to blocked beds in shared rooms did not occur. Table 3 breaks down the different cost categories.
The annual MDRO-related costs varied in nursing homes between $€ 2449.72$ and $€ 153263.74$ (mean $€ 50$ 306.82, SD €44 873.89). As shown in figure 1, annual costs differed over the nursing homes. In addition, in four of the six participating nursing homes, costs were rising in every year.

\section{Revenue data}

An average monthly reimbursement of $€ 2500$ per bed was assumed. This resulted in an average annual income of €2.1-€3.6 million per nursing home. For the observation period, the calculated MDRO costs make up a small but increasing share of the revenues over the 3 years: $1.15 \%$ (2011), $1.72 \%$ (2012) and $2.30 \%$ (2013). A variation between the individual houses could also be shown.

\section{DISCUSSION}

This study analyses the economic burden of multidrug-resistant pathogens in nursing homes in Germany for the first time. Our results confirm that MDROs have a clinical and an economic significance in healthcare facilities apart from hospitals. The analysis was conducted from the microeconomic perspective of a nursing home. Despite a lower amount of daily costs (€76.23 vs up to $€ 604.58$ in hospitals ${ }^{21}$ ), nursing homes have to deal with total costs of $€ 12682.23$ per MDRO case. This sum is similar to results of previous cost analysis in hospitals. ${ }^{13} 142223$

Owing to lack of evidence, only a comparison with data of the hospital sector is possible. Additional workload and expenses for hygiene materials represent the largest cost items in nursing homes. These costs were measured in a similar amount of $€ 108.46$ per day in our previous cost analysis of MRSA in hospitals. ${ }^{14}$ However, there is a central difference regarding opportunity costs

Table 1 Overview of data of demographic and surveillance parameters of the six participating nursing homes

\begin{tabular}{|c|c|c|c|c|c|c|c|}
\hline & \multicolumn{6}{|c|}{ Nursing home } & \multirow[b]{2}{*}{ Mean (SD \pm ) } \\
\hline & 1 & 2 & 3 & 4 & 5 & 6 & \\
\hline Number of beds & 93 & 96 & 70 & 100 & 120 & 92 & $95.2( \pm 14.6)$ \\
\hline Resident days (total) & 101836 & 105121 & 76651 & 109501 & 131401 & 100741 & $104208.5( \pm 16048.6)$ \\
\hline MDRO cases & 13 & 7 & 6 & 21 & 19 & 5 & $11.8( \pm 6.3)$ \\
\hline MRSA cases & 13 & 6 & 6 & 19 & 13 & 3 & $10.0( \pm 5.5)$ \\
\hline $\begin{array}{l}\text { Gram-negative bacteria cases } \\
(3-M R G N, 4-M R G N)\end{array}$ & NK & 1 & 0 & 2 & 6 & 2 & $2.2( \pm 2.0)$ \\
\hline Number of MDRO-positive days & 1242 & 1039 & 2025 & 3206 & 4141 & 140 & $1965.5( \pm 1353.3)$ \\
\hline 2011 & 692 & 45 & 530 & 647 & 448 & 75 & $381.4( \pm 257.2)$ \\
\hline 2012 & 264 & 421 & 731 & 822 & 1641 & 26 & $650.8( \pm 517.8)$ \\
\hline 2013 & 276 & 573 & 744 & 1701 & 1986 & 39 & $886.5( \pm 716.7)$ \\
\hline Number of MRSA-positive days & 1242 & 1027 & 2025 & 2824 & 2723 & 90 & $1655.2( \pm 971.1)$ \\
\hline Number of MRGN-positive days & NK & 12 & 0 & 382 & 1418 & 50 & $372.4( \pm 541.4)$ \\
\hline $\begin{array}{l}\text { Average duration per MDRO-ca } \\
\text { (in days) }\end{array}$ & 95.5 & 148.4 & 337.5 & 152.7 & 218.0 & 28.0 & $163.3( \pm 97.1)$ \\
\hline
\end{tabular}


Table 2 Average duration of MRSA cases and MRSA ratios in different healthcare facilities

\begin{tabular}{|c|c|c|c|}
\hline & $\begin{array}{l}\text { Average } \\
\text { duration of } \\
\text { MRSA cases }\end{array}$ & $\begin{array}{l}\text { MRSA } \\
\text { incidence } \\
\text { density }\end{array}$ & $\begin{array}{l}\text { MRSA } \\
\text { burden }\end{array}$ \\
\hline Hospital (all)* & 12.67 & 1.44 & 1.82 \\
\hline $\begin{array}{l}\text { Hospital }^{*} \text { (small, } \\
<400 \text { beds) }\end{array}$ & 13.38 & 1.51 & 2.01 \\
\hline Reha* & 21.43 & 0.485 & 1.03 \\
\hline Nursing home & 163.3 & 0.094 & 1.60 \\
\hline
\end{tabular}

(revenue losses due to blocked beds during isolation and prolongation of stay), which have been postulated as the main cost driver in hospitals. ${ }^{13}{ }^{14}$ Isolation costs caused by blocked beds were not calculated in this study. In contrast to hospitals, strict isolation (ie, isolation in single rooms) is not recommended in nursing homes in Germany. This is in line with the KRINKO recommendations $^{12}$ and shows that these recommendations are implemented. While most nursing homes try to provide single rooms for MDRO carriers, we have used a conservative approach of cost calculation to better reflect the higher cost of this.

Data to calculate specific MRSA ratios (MRSA incidence density and MRSA burden) in nursing homes, as they have been routinely collected in Germany by the MRSA-KISS system for hospitals and rehabilitation facilities for some years, are not yet available. Our study shows with 0.094 MRSA cases per 1000 resident days a lower MRSA incidence density in comparison to German hospitals (1.44 and 1.51, respectively; table 2). Nevertheless, the MRSA burden is with 1.60 MRSA davs per 100 resident days, only slightly lower than in hospitals (1.82 and 2.01) and higher than in rehabilitation facilities (1.03) caused by the long duration of MRSA cases in nursing homes (table 2). Moreover, chances to detect MRSA and other MDROs in long-term care facilities are much lower than in hospitals, as specific microbiological diagnostic is not performed there and patients with signs of severe infection are very likely referred to hospitals. Therefore, the true incidence can be expected to be much higher.

In this study, stronger differences were observed in the average duration of MRSA cases between the different healthcare facilities. The comparison of KISS figures (table 2) showed multiple increased values in nursing homes. While in hospitals and rehabilitation facilities, a patient with positive MRSA is discharged after completing their treatment regardless of the MRSA status, residents remain in the nursing home.

There is little published of the successful implementation of decolonization treatments of MRSA carriers in nursing homes. Generally, success of decolonisation measures in nursing homes is estimated in the literature to be very poor. ${ }^{11}$ The reasons given are on the one hand bad

Table 3 Cost distributions, divided in fall fix costs and daily costs

\begin{tabular}{|c|c|c|c|c|}
\hline \multirow[b]{2}{*}{ Fall fix costs } & \multicolumn{2}{|l|}{ Costs } & \multicolumn{2}{|l|}{ Costs } \\
\hline & Per case $^{\star}$ & Daily costs & Per day & Per case $^{\star}$ \\
\hline Information dissemination & $€ 96.52$ & $\begin{array}{l}\text { Isolation opportunity costs (blocked } \\
\text { beds in shared rooms) }\end{array}$ & $€ 0$ & $€ 0$ \\
\hline Figureheads & $€ 6.66$ & Isolation materials & $€ 24.70$ & $€ 4033.51$ \\
\hline Info sheets & $€ 13.31$ & Caps & $€ 2.39$ & $€ 390.29$ \\
\hline Informative consultations of staff & $€ 55.47$ & Masks & $€ 2.91$ & $€ 475.20$ \\
\hline Informative consultations of others & $€ 21.08$ & Coats & $€ 16.79$ & $€ 2741.81$ \\
\hline $\begin{array}{l}\text { Medical equipment (opportunity costs } \\
\text { for patient-related uses) }\end{array}$ & $€ 137.35$ & Glows & $€ 1.19$ & $€ 194.33$ \\
\hline Sphygmomanometer with stethoscope & $€ 60.00$ & Foot lets & $€ 1.42$ & $€ 231.89$ \\
\hline Heart rate monitor & $€ 4.35$ & Staff capacity & $€ 43.95$ & $€ 7177.04$ \\
\hline Blood glucose meter & $€ 35.00$ & Cleaning & $€ 2.22$ & $€ 362.53$ \\
\hline Thermometer & $€ 38.00$ & $\begin{array}{l}\text { Donning and doffing of personal } \\
\text { protective equipment }\end{array}$ & $€ 41.73$ & $€ 6814.51$ \\
\hline \multirow[t]{10}{*}{ Total of fall fix costs } & $€ 233.87$ & Disinfection material & $€ 1.78$ & $€ 290.67$ \\
\hline & & Hand disinfection & $€ 0.20$ & $€ 32.66$ \\
\hline & & Surface disinfection & $€ 1.08$ & $€ 176.36$ \\
\hline & & Clothes disinfection & $€ 0.50$ & $€ 81.65$ \\
\hline & & Laundry & $€ 4.92$ & $€ 440.91$ \\
\hline & & Towel (8 times daily) & $€ 2.22$ & $€ 362.53$ \\
\hline & & Bath towel (once a week) & (Daily share €0.07) & $€ 11.43$ \\
\hline & & Bed linen & $€ 2.63$ & $€ 429.48$ \\
\hline & & Preparation of special diet & $€ 0.88$ & $€ 143.70$ \\
\hline & & Total of daily costs & $€ 76.23$ & $€ 12448.36$ \\
\hline
\end{tabular}




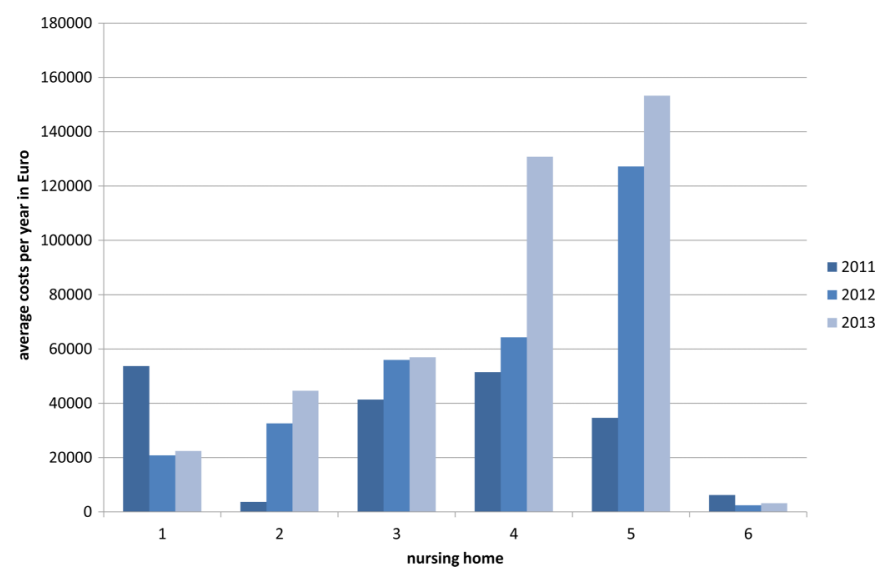

Figure 1 Multidrug-resistant organism-related costs per year (2011-2013) and nursing homes (1-6).

health conditions of elderly residents combined with bad compliance and on the other hand a lack of hygienic knowledge of the nursing staff. The successful decolonisation of MRSA cannot be achieved in any case, and not always in the first decolonisation cycle. This could be an explanation for the relatively long average duration of MRSA cases in nursing homes. The contradictory study by Kotilainen $e t a l^{24}$ showed that MRSA eradication can be carried out effectively in nursing homes. A consistent implementation of remedial measures including an appropriate staff training could help to increase the remediation rates and thus would reduce the duration and cost of MRSA cases in nursing homes.

There are limitations in the study which must be considered. The number of participating nursing homes is small. Also, there was a strong regional limitation on the north-eastern part of Germany. An expansion of the study population, especially to other regions, would weaken the influence of regional epidemiological characteristics. Different residents' clientele (eg, variation in levels of care and grad of multimorbidity) may explain the differences between the individual longterm care facilities (figure 1). Again, a larger number of participants would have the influences better balanced.

Since no screening was performed concomitantly to the study, it must be assumed that not all MDRO cases were detected. In these cases, no protective measures were carried out and therefore no costs primarily incurred for the nursing home. However, this may lead to transmission of pathogens to other residents, which increases risk and costs of MDRO cases in future.

There was no information about the variation costs between the different multidrug-resistant pathogens. The considered hygienic processes are almost the same for all pathogens; thus, the additional costs per day should be comparably high. Nevertheless, differences could occur in the average duration of cases as shown in hospital data before. ${ }^{25}$

The MDRO-positive patients were not directly compared with a control group of patients who were not infected or colonised. The study only identified and evaluated additional hygiene processes regarding MRDO. A comparison of both groups of residents would have depicted the additional costs possibly more accurately because other diseases could also require standard hygienic precautions such as the use of personal protective equipment. This consideration would have partially reduced the calculated MDRO-related costs. However, this proportion may be regarded as negligible. Also, any specific medication, mainly the treatment with antibiotics, was not included in the analysis as it only addressed hygienic measures.

MRSA occurred most frequently, which is a well-known and still manageable pathogen. However, cases have already been demonstrated with multidrug-resistant Gram-negative pathogens in nursing homes. Most Gram-negative MRDOs reported were 3-MRGN, but a 4-MRGN was detected in one resident too. An increase in MDRO cases could also be observed over the 3 years. Our data show that healthcare providers have to be aware of the problem of multidrug-resistant bacteria not only in hospitals but also in other healthcare facilities such as nursing homes. Clinics, rehabilitation facilities and nursing homes are closely linked since residents are frequently transferred between them, which significantly contributes to the transmission of the pathogen. ${ }^{26}$ It must be the responsibility of politics to take up this development and to provide the necessary resources to combat the spread of multidrug-resistant pathogens in the community. The evaluation of the real costs caused by MDROs is the first step to implement an efficient sustainable management.

Acknowledgements The authors thank the six participating nursing homes, which may not be named for reasons of data protection.

Contributors $\mathrm{CH}$ and SF designed and supervised the study. MR collected and $\mathrm{CH}$ and $\mathrm{MR}$ analysed the data. $\mathrm{CH}$ took literature search and drafted the manuscript. All authors wrote and revised the paper and approved the final version.

Funding This work is integrated in the model project Health, Innovative Care and Regional Economy (HICARE), Health Region Baltic Sea Coast, which is supported by German Federal Ministry of Education and Research (01KQ1001C) and the Ministry of Education, Science and Culture of the state Mecklenburg-Western Pomerania (UG11009).

Competing interests None declared.

Provenance and peer review Not commissioned; externally peer reviewed.

Data sharing statement No additional data are available.

Open Access This is an Open Access article distributed in accordance with the Creative Commons Attribution Non Commercial (CC BY-NC 4.0) license, which permits others to distribute, remix, adapt, build upon this work noncommercially, and license their derivative works on different terms, provided the original work is properly cited and the use is non-commercial. See: http:// creativecommons.org/licenses/by-nc/4.0/

\section{REFERENCES}

1. Pfingsten-Wurzburg S, Pieper DH, Bautsch W, et al. Prevalence and molecular epidemiology of methicillin-resistant Staphylococcus aureus in nursing home residents in northern Germany. J Hosp Infect 2011;78:108-12. 
2. Greenland K, Rijnders MI, Mulders M, et al. Low prevalence of methicillin-resistant Staphylococcus aureus in Dutch nursing homes. $J$ Am Geriatr Soc 2011;59:768-9.

3. Reynolds C, Quan V, Kim D, et al. Methicillin-resistant Staphylococcus aureus (MRSA) carriage in 10 nursing homes in Orange County, California. Infect Control Hosp Epidemiol 2011;32:91-3.

4. Benenson S, Cohen MJ, Block C, et al. Vancomycin-resistant enterococci in long-term care facilities. Infect Control Hosp Epidemiol 2009;30:786-9.

5. Rooney PJ, O'Leary MC, Loughrey AC, et al. Nursing homes as a reservoir of extended-spectrum beta-lactamase (ESBL)-producing ciprofloxacin-resistant Escherichia coli. J Antimicrob Chemother 2009;64:635-41.

6. Murphy CR, Hudson LO, Spratt BG, et al. Predicting high prevalence of community methicillin-resistant Staphylococcus aureus strains in nursing homes. Infect Control Hosp Epidemiol 2013;34:325-6.

7. KRINKO. Commission for Hospital Hygiene and Infection Prevention at the Robert-Koch Institute: Empfehlungen zur Prävention und Kontrolle von Methicillinresistenten Staphylococcus aureus-Stämmen (MRSA) in Krankenhäusern und anderen medizinischen Einrichtungen. Bundesgesundheitsblatt Gesundheitsforschung Gesundheitsschutz 1999;42:954-8.

8. Engelhart ST, Hanses-Derendorf L, Exner M, et al. Prospective surveillance for healthcare-associated infections in German nursing home residents. J Hosp Infect 2005;60:46-50.

9. Köck R. Zum Aufwand von MRSA-Screeninguntersuchungen in deutschen Krankenhäusern. Epidemiologisches Bull 2013;23: 41-4.

10. Peters $\mathrm{C}$, Schablon $\mathrm{A}$, Bollongino $\mathrm{K}$, et al. Multiresistant pathogens in geriatric nursing-infection control in residential facilities for geriatric nursing in Germany. GMS Hyg Infect Control 2014;9:Doc22.

11. Ruscher $\mathrm{C}$, Schaumann R, Mielke M. Herausforderungen durch Infektionen und mehrfach-resistente Bakterien bei alten Menschen in Heimen. Bundesgesundheitsblatt Gesundheitsforschung Gesundheitsschutz 2012;55:1444-52.

12. KRINKO. Infektionsprävention in Heimen: Empfehlung der Kommission für Krankenhaushygiene und Infektionsprävention beim Robert Koch-Institut (RKI). Bundesgesundheitsblatt Gesundheitsforschung Gesundheitsschutz 2005;48:1061-80.

13. Herr CE, Heckrodt TH, Hofmann FA, et al. Additional costs for preventing the spread of methicillin-resistant Staphylococcus aureus and a strategy for reducing these costs on a surgical ward. Infect Control Hosp Epidemiol 2003;24:673-8.

14. Hubner C, Hubner NO, Hopert K, et al. Analysis of MRSA-attributed costs of hospitalized patients in Germany. Eur J Clin Microbiol Infect Dis 2014:33:1817-22.

15. de Kraker ME, Davey PG, Grundmann H. Mortality and hospital stay associated with resistant Staphylococcus aureus and Escherichia coli bacteremia: estimating the burden of antibiotic resistance in Europe. PLoS Med 2011;8:e1001104.

16. van Rijen MM, Kluytmans JA. Costs and benefits of the MRSA Search and Destroy policy in a Dutch hospital. Eur J Clin Microbiol Infect Dis 2009;28:1245-52.

17. Capitano $\mathrm{B}$, Leshem $\mathrm{OA}$, Nightingale $\mathrm{CH}$, et al. Cost effect of managing methicillin-resistant Staphylococcus aureus in a long-term care facility. J Am Geriatr Soc 2003;51:10-16.

18. Flessa S. Grundzüge der Krankenhausbetriebslehre-Band 2 [in German]. München: Oldenbourg Wissenschaftsverlag, 2014.

19. Charberny IF, Gstmeier P. How to present MRSA data most appropriately? Hyg Med 2007;32:10-14.

20. Destatis. Pflegestatistik 2011. 2013. https://www.destatis.de/DE/ Publikationen/Thematisch/Gesundheit/Pflege/PflegeDeutschlander gebnisse5224001119004.pdf?_blob=publicationFile

21. Tubbicke A, Hubner C, Kramer A, et al. Transmission rates, screening methods and costs of MRSA-a systematic literature review related to the prevalence in Germany. Eur J Clin Microbiol Infect Dis 2012;31:2497-511.

22. Resch A, Wilke M, Fink C. The cost of resistance: incremental cost of methicillin-resistant Staphylococcus aureus (MRSA) in German hospitals. Eur J Health Econ 2009;10:287-97.

23. Wernitz MH, Keck S, Swidsinski S, et al. Cost analysis of a hospital-wide selective screening programme for methicillin-resistant Staphylococcus aureus (MRSA) carriers in the context of diagnosis related groups (DRG) payment. Clin Microbiol Infect 2005;11:466-71.

24. Kotilainen $\mathrm{P}$, Routamaa M, Peltonen $\mathrm{R}$, et al. Eradication of methicillin-resistant Staphylococcus aureus from a health center ward and associated nursing home. Arch Intern Med 2001;161:859-63.

25. Zimlichman E, Henderson D, Tamir O, et al. Health care-associated infections: a meta-analysis of costs and financial impact on the US health care system. JAMA Intern Med 2013;173:2039-46.

26. Lee BY, Bartsch SM, Wong KF, et al. The importance of nursing homes in the spread of methicillin-resistant Staphylococcus aureus (MRSA) among hospitals. Med Care 2013;51:205-15. 